\title{
Systemic atrioventricular valve replacement with a Melody valve in an infant with a single-ventricle physiology
}

Shuhua Luo, MD, PhD, ${ }^{\mathrm{a}, \mathrm{b}, \mathrm{c}}$ Glen S. Van Arsdell, MD, ${ }^{\mathrm{a}, \mathrm{b}}$ and Osami Honjo, MD, PhD, ${ }^{\mathrm{a}, \mathrm{b}}$ Toronto, Ontario, Canada, and Chengdu, China

\footnotetext{
From the ${ }^{\mathrm{a}}$ Division of Cardiovascular Surgery, Labatt Family Heart Centre, The Hospital for Sick Children, Toronto, Ontario, Canada; the bepartment of Surgery, University of Toronto, Toronto, Ontario, Canada, and the ${ }^{\mathrm{c}}$ Department of Cardiovascular Surgery, West China Hospital of Sichuan University, Chengdu, China. Read at the 98th Annual Meeting of The American Association for Thoracic Surgery, San Diego, California, April 28-May 1, 2018.

Disclosures: Authors have nothing to disclose with regard to commercial support.

Received for publication June 1, 2018; revisions received June 1, 2018; accepted for publication June 10, 2018; available ahead of print Aug 14, 2018.

Address for reprints: Osami Honjo, MD, PhD, Division of Cardiovascular Surgery, Labatt Family Heart Center, The Hospital for Sick Children, 555 University Ave, Toronto M5G1X8, Ontario, Canada (E-mail: osami. honjo@sickkids.ca).

J Thorac Cardiovasc Surg 2018;156:e211-3

$0022-5223 / \$ 36.00$

Copyright (C) 2018 Published by Elsevier Inc. on behalf of The American Association for Thoracic Surgery https://doi.org/10.1016/j.jtcvs.2018.06.036
}

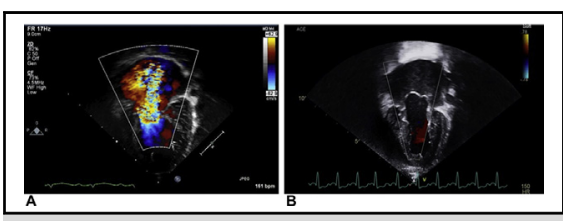

Severely regurgitant AV valve replaced with the Melody valve had good follow-up function.

\section{Central Message}

A Melody valve can be safely implanted in an infant with a functional single-ventricle physiology without significant residual anatomic lesions and with reasonable short-term functional outcome.

See Editorial Commentary page e215.
Video clip is available online.

Atrioventricular (AV) valve regurgitation poses a significant risk for the infant with single-ventricle physiology. ${ }^{1}$ Traditional replacement options for an irreparable systemic $\mathrm{AV}$ valve are associated with high surgical mortality, high risks of valve thrombosis, and heart block. ${ }^{2}$ The Melody valve (Medtronic, Inc, Minneapolis, Minn), which was originally designed for percutaneous pulmonary valve replacement, is an alternative artificial valve of choice, with its potential advantages including larger effective orifice area, no anticoagulation requirement, and lower thrombogenic profile. ${ }^{3}$

A 3-month-old, 3.2-kg infant with unbalanced AV septal defect and a dominant left ventricle had severe AV valve regurgitation and borderline ventricular function and was listed for heart transplantation (Video 1). He had previously undergone a modified Blalock-Taussig shunt, followed by $\mathrm{AV}$ valve repair. Because of worsening AV valve regurgitation and congestive heart failure, the patient required mechanical ventilation, inotropic support, and peritoneal drainage. The decision was made to proceed with AV replacement with a Melody valve in an attempt to keep the patient on the transplant list without further end-organ injury.

Before the sternotomy, we prepared the Melody valve with wedge resection of 3 stents, and a 4-mm polytetrafluoroethylene tube graft (W. L. Gore \& Associates, Inc, Flagstaff, Ariz) was sewn around the valve as a cuff (Figure 1). The purpose of the wedge resection was to avoid the systemic ventricular outflow tract (SVOT) obstruction. All AV valve leaflets except the superior bridging leaflet were preserved. The Melody valve was compressed longitudinally to fit in the annulus. It was

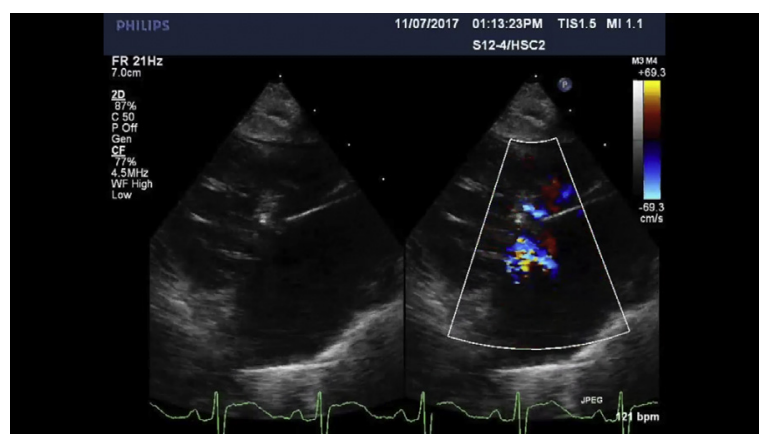

VIDEO 1. Preoperative transthoracic echocardiography demonstrated severe atrioventricular valve regurgitation with a board-centered jet. The free edge of the atrioventricular valve was thickened and dysplastic. Ventricular systolic function was preserved in the context of severe atrioventricular valve regurgitation. Video available at: https://www. jtcvs.org/article/S0022-5223(18)31781-1/fulltext. 

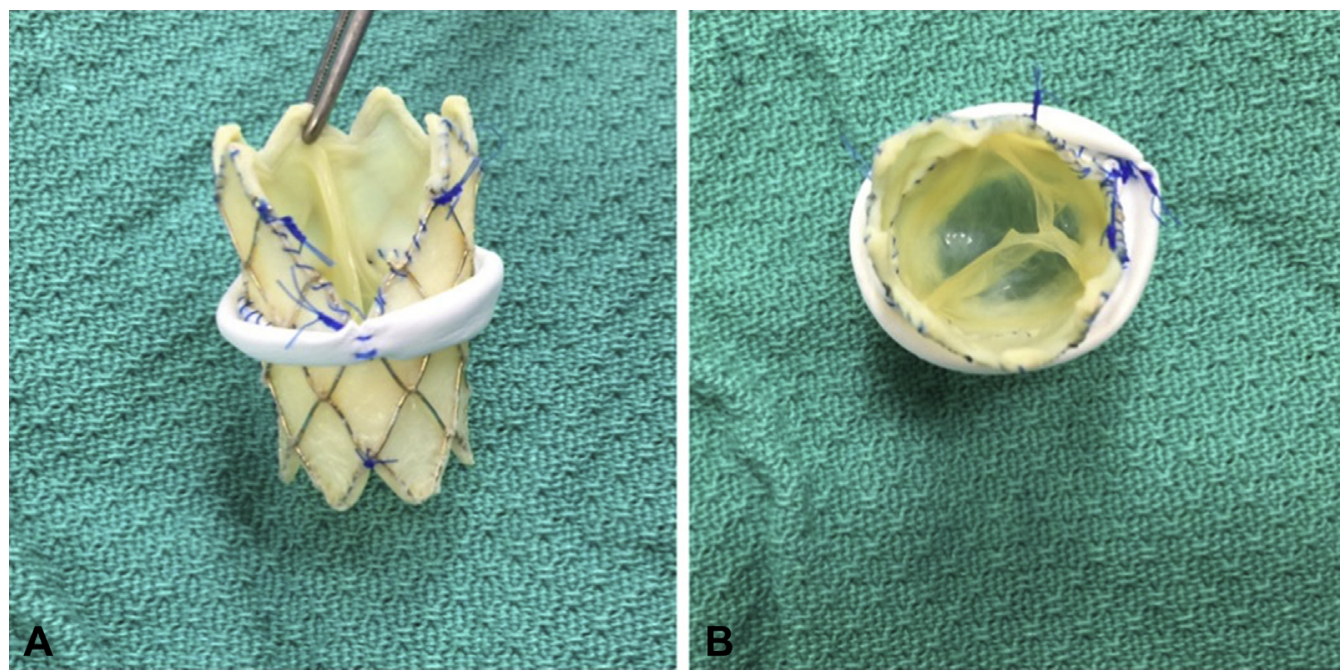

FIGURE 1. The Melody valve preparation. The Melody valve was predilated to $20 \mathrm{~mm}$ according to the measurement of atrioventricular annular size on echocardiography. Three stents were resected as a wedge resection (A). The resected edge was reinforced, and a 4-mm polytetrafluoroethylene graft was sewn around the valve as a cuff (B).

critically important to align the wedge resection part with the SVOT (Video 2). After the valve was taken down to the annulus and secured by interrupted sutures, the Melody valve was dilated to $20 \mathrm{~mm}$ according to the intraoperative measurement (Video 3). Cardiopulmonary bypass time was 84 minutes, and aortic crossclamp time was 64 minutes. The patient came off bypass easily with low-dose inotropic support. Postoperative echocardiography demonstrated trivial AV valve regurgitation, with no paravalvular leak and no inflow gradient. The SVOT was completely unobstructed, with a peak gradient of $16 \mathrm{~mm} \mathrm{Hg}$ and good left ventricular systolic function (Video 4). The patient was extubated 4 days after surgery. After several days of various degrees of $\mathrm{AV}$ block, the patient regained sinus rhythm. The follow-up echocardiogram at 7 months after

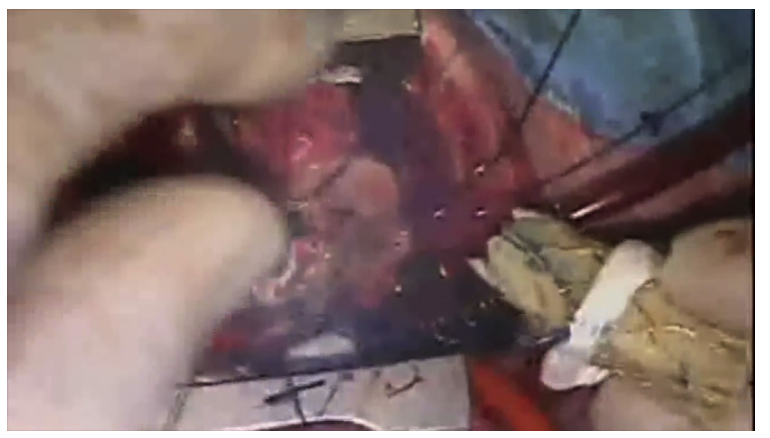

VIDEO 2. The Melody valve was compressed so that it could be placed into the atrioventricular valve annulus. Care was taken to exert equal tension to compress the Melody valve longitudinally to avoid stent distortion, and also to match the wedge resection part with the anatomic position of the systemic ventricular outflow tract. Video available at: https://www.jtcvs.org/article/S0022-5223(18)31781-1/fulltext. implantation showed good function of the Melody valve and a patent SVOT. The patient is currently awaiting transplant.

This case demonstrates the feasibility of the Melody valve implantation in the systemic $\mathrm{AV}$ valve position in an infant with a functional single-ventricle physiology. The rationale of exploring the Melody valve option rather than conventional replacement with a mechanical valve was to avoid valve thrombosis and heart block, thereby achieving a higher probability of heart transplant without valve-related complications while on the waiting list. Because of the relatively high incidence of $\mathrm{AV}$ valve regurgitation in the single-ventricle population, and the finding that $\mathrm{AV}$ valve regurgitation or ventricular

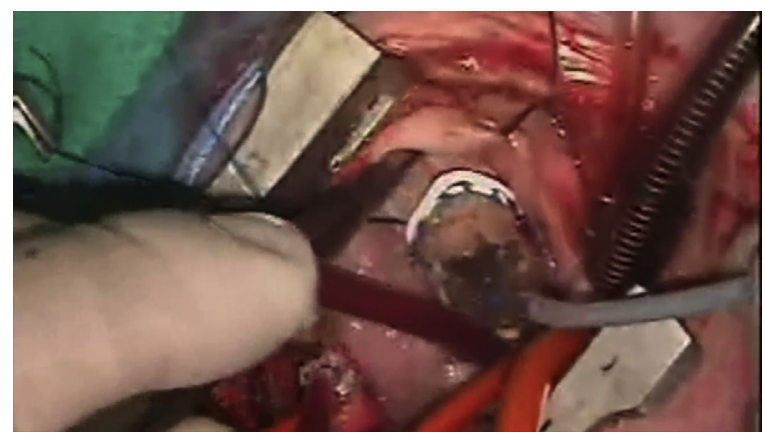

VIDEO 3. The balloon catheter was carefully inserted into the ventricle, and the balloon was dilated to $20 \mathrm{~mm}$, which was determined by direct measurement of the atrioventricular valve annulus with a Hegar sizer. The tip of the stent was often not completely dilated, and a second dilation was therefore required. A saline solution test was performed to confirm a competent Melody valve. Video available at: https://www.jtcvs.org/ article/S0022-5223(18)31781-1/fulltext. 


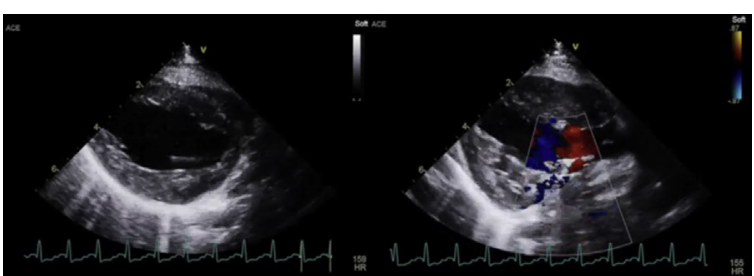

VIDEO 4. Follow-up echocardiography at 7 months after surgery showed trivial regurgitation of the Melody valve, with no paravalvular leak and no inflow gradient. The left ventricular outflow tract was completely unobstructed, with good left ventricular systolic function. Video available at: https://www.jtcvs.org/article/S0022-5223(18)31781-1/fulltext.

dysfunction is among the most common indications for heart transplant listing, this strategy with a Melody valve may play an important role in palliating the failing single ventricle for patients on the transplant list. The valve was inserted in reasonable operative time and with no major technical difficulty.

The early outcome of the Melody valve replacement in the mitral valve position in a biventricular circulation is favorable ${ }^{3}$; however, the outcome of the Melody valve replacement in patients with single-ventricle physiology is largely unknown. The case described here demonstrated that the Melody valve can be successfully implanted in a patient with such a complex condition without significant residual anatomic lesions, and the short-term functional outcome is acceptable. At this point, this strategy serves as a bridge to transplant in our institution, because the long-term durability of the Melody valve in the systemic AV valve position is unknown. Nonetheless, it is conceivable that the strategy may be used as an adjunctive treatment in the staged single-ventricle palliation of patients with irreparable AV valve regurgitation.

\section{References}

1. Honjo O, Atlin CR, Mertens L, Al-Radi OO, Redington AN, Caldarone CA, et al. Atrioventricular valve repair in patients with functional single-ventricle physiology: Impact of ventricular and valve function and morphology on survival and reintervention. J Thorac Cardiovasc Surg. 2011;142:326-35.e2.

2. Mahle WT, Gaynor JW, Spray TL. Atrioventricular valve replacement in patients with a single ventricle. Ann Thorac Surg. 2001;72:182-6.

3. Freud LR, Marx GR, Marshall AC, Tworetzky W, Emani SM. Assessment of the Melody valve in the mitral position in young children by echocardiography. J Thorac Cardiovasc Surg. 2017;153:153-60.e1. 